\title{
OS OBJETIVOS \\ DO TRATAMENTO PSICANALÍTICO \\ PARA FREUD E PARA WINNICOTT
}

Neste artigo pretende-se apresentar os aspectos gerais, teóricos $e$ descritivos dos objetivos do tratamento psicanalitico para Freud e Winnicott, para, ao final, explicitar algumas continuidades e rupturas nas suas concepcões sobre qual seria o objetivo do processo psicoterapêutico psicanalitico. Nesse sentido, procura mostrar que Freud pensa o objetivo do tratamento psicanalítico em termos de uma estabilidade do en nas relações interpessoais, pressionadas pela vida instintual e pelos valores superegoicos (também referidos à sexualidade), enunciado tanto de forma metapsicológica quanto descritiva, tendo em vista a diminuição do sofrimento; $e$ Winnicott, numa ampliação da proposta de Freud, aponta esse objetivo para além da vida instintual ou sexual (mas sem deixar de considerá-la), buscando a conquista de um lugar para ser e continuar sendo, sentir-se real e levando a própria vida, ainda que isso possa ser sofrido. Descritores: Frend; Winnicott; tratamento; sofrimento; continuidade de ser.

\section{Leopoldo Fulgencio}

DOI: https://doi.org/10.11606/issn. 1981-1624.v23i2p344-361.

A

onde o psicanalista espera levar o paciente ao longo e ao fim de um tratamento psicanalítico? Qual é o horizonte (o telos) na direção do qual se voltam todos os seus esforços? É comum dizer que a psicanálise não foca sua atenção na eliminação de um determinado sintoma (ou conjunto de sintomas), dado que, não modificada a causa ou causas que geram os sintomas, estes seriam substituídos por outros, migrando de um modo de expressão sintomática para outro. Mas quais seriam, mais especificamente, em termos descritivos e teóricos, esses objetivos? Delimitando minha análise a dois autores clássicos - em primeiro, e necessariamente, seu fundador e, em segundo, um dos autores 
reconhecidos como tendo arejado o espírito clínico da psicanálise -, proponho apresentar suas descrições desses objetivos e, ao final, comentar algumas das suas semelhanças e diferenças.

\section{Parte I - Os objetivos do tratamento psicanalítico para Freud}

$\mathrm{Na}$ primeira parte desse artigo procura-se indicar os objetivos do tratamento psicanalítico para Freud, mostrando que ele os apresenta de duas maneiras: uma em termos descritivos, e outra em termos metapsicológicos. Em termos descritivos, trata-se de levar o paciente à capacidade de agir e aproveitar da existência; em termos metapsicológicos, de fortalecer o ego para que esse tenha maior autonomia em relação às pressões advindas do id e do superego.

Muito antes de Freud já se sabia que grande parte da vida psíquica não era dada à consciência e que essas partes inconscientes determinavam pensamentos, sentimentos e ações dos homens (cf. Ellenberger, 1970). No entanto, Freud foi o primeiro a articular a noção de inconsciente e a importância da sexualidade na compreensão da gênese da organização psíquica dos indivíduos, tanto saudáveis como doentes, e a criar um método de tratamento psicoterápico fundado na importância da relação afetiva médico-paciente. Ao sintetizar esses elementos, Freud (1923/2001b, 1914/2001)criou a psicanálise como método de tratamento fundado no reconhecimento dos processos psíquicos inconscientes, no valor dado à sexualidade e ao complexo de Édipo na infância (e ao longo de toda a vida dos seres humanos) e no reconhecimento dos fenômenos da transferência e da resistência (quando se tenta, pelo método de tratamento psicanalítico, acessar o inconsciente na história de vida dos pacientes).

Todo método de tratamento implica, necessariamente, uma concepção do que são as doenças (suas gêneses, suas dinâmicas) e o tipo de solução a ser dada ou procurada para tratar dessas doenças ou sintomas. De modo geral, pode-se considerar que as psicopatologias são, para Freud, um tipo de constrição, uma limitação interna (psicológica, derivada de conflitos internos), que rouba do indivíduo, insistentemente, recursos importantes para que ele possa estar no mundo e se relacionar consigo e com os outros.

Ao se referir às psicopatologias como funcionamento que drena os recursos existenciais dos indivíduos, Freud (1911-1913/2001a) diz que "nada na vida é tão caro quanto a doença e... a burrice" (p. 133), talvez considerando também a burrice com um tipo de manifestação neurótica. Para ele, a psicanálise seria, fundamentalmente, um tratamento que visa poupar o doente dessa despesa psíquica (Freud, 1923/2001b). 
Mas onde Freud quer que seus pacientes cheguem? Por um lado, ele dá algumas referências empíricas e, por outro, especifica seus objetivos em termos teóricos. Do ponto de vista descritivo, Freud espera que seus pacientes deixem de sofrer excessivamente, ou seja, que possam transformar suas misérias psiconeuróticas em infelicidades banais e, com isso, tendo um psiquismo recuperado, possam estar mais aptos para lutar contra os sofrimentos inerentes à vida (Freud \& Breuer, 1893-1895/2009)1.

Freud não procura a eliminação dos sintomas, mas a recuperação da autonomia do paciente (1911-1913/2001b) ou da sua capacidade de agir na vida (1998/1911). Escrevendo a Ferenczi, em 1911, ele diz: "Não se deve lutar por eliminar os complexos, mas por colocar-se de acordo com eles: os complexos são, legitimamente, aquilo que dirige a conduta de um homem no mundo" (Freud \& Ferenczi, 1992, carta de 17 nov. 1911). O que Freud está procurando é o reestabelecimento das condições psíquicas do indivíduo para que ele mesmo possa lutar contra seus sofrimentos, ou seja, Freud não visa à cura, propriamente dita, mas dar condições para que o paciente possa ele mesmo se curar (cf. Freud \& Breuer, 1893-1895/2009).

Em certo sentido, mesmo se colocando num ponto de vista determinista, isso não faz Freud excluir a questão da liberdade para agir (cf. Gay, 1990). Para ele, o tratamento analítico tem como objetivo diminuir uma constrição (pelos conflitos da realidade psíquica interna) do indivíduo, restituindo-lhe maior liberdade para escolher agir, ainda que as formações do inconsciente (e mesmo alguns sintomas) possam sempre estar presentes: "A ação da análise não torna as reações mórbidas impossíveis, mas procura fornecer ao eu do doente a liberdade para se decidir por isto ou aquilo" (1923/2001a, p. 59n).

Ao falar de modo sintético, designando dois índices objetivos da saúde psíquica, Freud se refere a capacidades ordinárias da vida social: a de agir (realizar) e a de aproveitar da existência (Freud, 1904/2001, 1913/2001). São essas capacidades que Freud espera poder reestabelecer para

346 Estilos clin., São Paulo, v. 23, n. 2, maio/ago. 2018, 344-361. 
que o próprio paciente possa conquistar um modo de vida mais proveitoso, no uso de suas forças e energias (Freud 1916/2001); conquistando "uma capacidade de atividade e de prazer, em geral, sem restrições" (1912/2001c, p. 236).

Afirmando que a própria noção de saúde só pode ser descrita em termos metapsicológicos (1937/2001), ou seja, que a saúde só pode ser descrita em termos das relações entre as supostas instâncias psíquicas, analisando a posição do ego em relação às exigências do id e do superego, ele descreve, então em termos teóricos, os objetivos do tratamento psicanalítico, a saber: "fortificar o eu, torná-lo mais independente do super-eu, aumentando seu campo de percepção e estendendo sua organização, de maneira que ele possa se apropriar de novos pedaços do Id. Ali onde era o Id, o Ego deve advir" (1933a, p. 80, lesson 31, grifos meus). Para fornecer um conteúdo intuitivo a esse enunciado metapsicológico, ele apresenta uma analogia explicativa: "Trata-se de um trabalho cultural, um pouco como a secagem do Zuyderzee" (Freud, 1933/2001, p. 80, lesson 31); ou seja, é como na Holanda que, ao construir os diques, possibilita secar uma região, antes invadida pelo mar, tornando-a habitável.

Ao considerar que determinadas formações psíquicas inconscientes são responsáveis pelos sintomas e sofrimentos neuróticos, Freud (1923/2001b) dirá que o tratamento psicanalítico visa: a supressão das resistências e o exame detalhado dos recalcamentos do doente, a unificação e o reforço o mais extenso de seu ego, de lhe poupar a despesa psíquica por seus conflitos internos, de dar forma, a partir do que ele é, ao melhor do que ele poder vir a ser em função de suas predisposições e capacidades, e de o tornar, tanto quanto possível, capaz de atividade e de prazer (p. 253).

É importante ressaltar que não há um objetivo moralizante, que Freud não está buscando normatizar ou fazer o indivíduo se adaptar ao mundo, que se torne um bom homem politicamente correto: "A análise visa à unidade, não necessariamente à bondade" (Hale Jr., 1971, p. 188)²

Depois de Freud, a questão da cura e dos objetivos do tratamento psicanalítico tem sido redescrita e reformulada de diversas maneiras, dentre elas, a de Winnicott, que parece descentrar os objetivos do processo analítico de sua referência predominante aos modos de administração da sexualidade e seus conflitos, nas relações interpessoais.

\section{Parte II - Os objetivos do tratamento analítico para Winnicott}

Pretendo, agora, comentar quais são os objetivos do tratamento psicanalítico para Winnicott, à luz da compreensão da sua ontologia (centrada na questão da necessidade da continuidade de ser) e de sua noção 
de saúde. Trata-se de mostrar que, para ele, grosso modo, um processo psicoterápico procura conduzir o indivíduo a uma integração tal que ele possa levar sua vida com autonomia e independência relativas, adaptando-se ao mundo sem perder demasiadamente sua espontaneidade, podendo responsabilizar-se por seus sucessos e fracassos ou falhas, e que tenha uma riqueza existencial e sociocultural.

\section{O modelo de homem para Winnicott}

O objetivo de Winnicott (1988/1990) é poder fazer um estudo da natureza bumana. E o que é essa natureza? $\mathrm{O}$ autor se refere a ela de diversas maneiras, mas sempre marcando que se trata de algo característico da própria humanidade, algo que não pode ser reduzido a outros tipos de existentes, tais como as máquinas ou, ainda, outros tipos de animais. $\mathrm{O}$ ser humano, a natureza humana, por essência tem a característica de fazer a si mesmo no tempo, produzindo (em termos de dar sentido a) a si e ao mundo em que vive.

As explicações e descrições que Winnicott procura fornecer correspondem aos aspectos universais dessa natureza. Mas, então, como é essa natureza humana, quais são os seus aspectos universais e seus fundamentos ontológicos? Em primeiro lugar, trata-se de algo propriamente humano, e não passível de ser reduzido a máquinas ou qualquer outra proposição que não seja propriamente humana, seja em termos formais, simbólicos ou matemáticos.

Procurando explicitar a posição de Winnicott, podemos retomar uma passagem em que ele define a questão do ser como um fundamento ontológico da natureza humana:

Gostaria de postular um estado de ser que é um fato no bebê normal, antes do nascimento e logo depois. Esse estado de ser pertence ao bebê, e não ao observador. A continuidade do ser significa saúde. Se tomarmos como analogia uma bolha, podemos dizer que, quando a pressão externa está adaptada à pressão interna, a bolha pode seguir existindo. Se estivéssemos falando de um bebê humano, diríamos "sendo". Se, por outro lado, a pressão no exterior da bolha for maior ou menor do que aquela em seu interior, a bolha passará a reagir à intrusão. Ela se modifica como reação a uma mudança no ambiente, e não a partir de um impulso próprio. Em termos do animal humano, isto significa uma interrupção no ser, e o lugar do ser é substituído pela reação à intrusão (Winnicott, 1988/1990, p. 148).

A experiência de ser, inicialmente a mais primitiva das experiências, mas que constitui um fundamento da existência, corresponde a uma experiência ativa, dado que "reagir interrompe o ser e o aniquila" (1960/1983, p. 67), na qual o indivíduo, sustentado pelo ambiente ou até mesmo respondendo a ele, não perde o ponto de apoio e referência (em si mesmo) a partir de onde age ou, noutros termos, segue sua existência sem

348 Estilos clin., São Paulo, v. 23, n. 2, maio/ago. 2018, 344-361. 
perder em demasia sua espontaneidade. Essa experiência de ser corresponde a um fundamento que faz a vida valer a pena ser vivida: "É somente pela continuidade da existência que o sentimento de si, do real, e o sentimento de ser podem finalmente se estabelecer enquanto traço da personalidade individual" (Freud, 1971/1999, p. 24).

Pode-se considerar que a noção de continuidade de ser tem como correlato a consideração da existência de uma tendência inata à integração ou ao crescimento, de modo que se pode afirmar que Winnicott (1958/1997) compreende a tendência inata à integração como sendo o que fornece o impulso em direção ao ser e ao continuar sendo.

A integração, em seus diversos aspectos (no tempo, no espaço, na associação psique-soma, da personalidade etc.), não está, no entanto, garantida por essa tendência, ou seja, há uma série de fatores que podem contribuir ou atrapalhar seu funcionamento.

É considerando, pois, a natureza humana como o ente que tem necessidade de ser e continuar sendo, impulsionado por uma tendência inata à integração, que Winnicott caracterizará, em termos ontológicos, o que é a vida socioemocional do homem. Mais ainda, ele integrará nessa concepção de natureza humana o fato de que o ser humano é um ser dependente e que isso é mais fundamental e constitucional do que a própria questão das excitações da vida instintual do homem: primeiro ser, mas o ser depende de ser-com e, depois, o fazer, inclusive o instintual.

Esse quadro também está associado a uma concepção de saúde, ou do que seria um modo de ser saudável do ser humano, o que não corresponde nem a um ser humano normal (ou normalizado), nem a um ser humano mediano (ou medíocre); caracterizando, assim, um telos para o desenvolvimento socioemocional e para os tratamentos psicoterápicos, seja este atingível ou não, em particular ou em geral.

\section{A noção de saúde para Winnicott}

Winnicott tem uma concepção descritiva da saúde socioemocional, evidentemente em consonância como o seu modelo ontológico. Ele diz, por exemplo:

A vida de um indivíduo são se caracteriza mais por medos, sentimentos conflitantes, dúvidas, frustrações do que por seus aspectos positivos. O essencial é que o homem ou a mulher se sintam vivendo sua própria vida, responsabilizando-se por suas ações ou inações, sentindo-se capazes de atribuírem a si o mérito de um sucesso ou a responsabilidade de um fracasso. Pode-se dizer, em suma, que o indivíduo saiu da dependência para entrar na independência ou autonomia (Winnicott, 1971/1999, p. 30). 
Podemos retomar aqui diversas referências de Winnicott à caracterização do que é o estado de saúde, procurando ampliar esse quadro descritivo: "De uma ou de outra forma nossa teoria inclui a crença de que viver criativamente constitui um estado saudável, e de que a submissão é uma base doentia para vida" (Winnicott, 1971/1975, p. 95); “o indivíduo pode tornar-se capaz de substituir o cuidado recebido por um cuidar-de-si-mesmo, e pode desta forma alcançar uma grande independência, que não é possível nem no extremo paranoide nem no extremo ingênuo" (Winnicott, 1988/1990, p. 146); são também aspectos da saúde a "capacidade de reparar danos" (1996/1997, pp. 236-237) e de "sentir-se deprimido" (Winnicott, 1971/1999, p. 17). Cabe, ainda, ressaltar que a saúde se diz muito mais em relação à riqueza ou pobreza da personalidade do que em relação a um estado em que não existam sintomas (Winnicott, 1971/1999).

Essa saúde ideal corresponde, por sua vez, a um desenvolvimento socioemocional ideal, de modo que aos estados patológicos corresponderá, como origem, a consideração de que o desenvolvimento não ocorreu: "o distúrbio psicológico é imaturidade, imaturidade do crescimento emocional do indivíduo, e esse crescimento inclui a evolução da capacidade do indivíduo para relacionar-se com pessoas e com o meio ambiente, de um modo geral" (1984/1999, pp. 
265-266). Essa concepção nos leva, então, a abordar o que é o tratamento psicoterápico, em termos dos processos de desenvolvimento que podem ser retomados numa psicoterapia psicanalítica: "Num contexto profissional, dado o comportamento profissional apropriado, pode ser que o doente encontre uma solução pessoal para problemas complexos da vida emocional e das relações interpessoais; o que fizemos não foi aplicar um tratamento, mas facilitar o crescimento" (1986/1999a, pp. 113-114).

\section{Objetivos do tratamento psicanalítico para Winnicott}

Quando Winnicott explicita quais seriam os objetivos do tratamento psicanalítico, o faz em linguagem e em perspectiva diferente da de Freud, ainda que estejam apoiadas nele. No seu texto dedicado a analisar os objetivos do tratamento psicanalítico, Winnicott aponta três grandes fases do tratamento: na primeira, o paciente desenvolve uma confiança no analista e no processo analítico, sentindo-se visto e entendido pelo profissional; na segunda, com base nessa confiança e sustentação ambiental, o paciente experimenta a si mesmo na relação com o analista e para além dela; e, na terceira, o paciente começa e conquista o sentimento de existir por si mesmo como algo natural (Winnicott, 1965/1983, p. 154). Esta última fase pode ser compreendida como o objetivo último de todo tratamento psicoterápico, ainda que seja um horizonte ideal e nem sempre alcançável.

Para Winnicott (1984/1999), o adoecimento corresponde a um tipo de imaturidade, uma interrupção no processo de desenvolvimento; e a psicoterapia, por sua vez, ao conjunto de ações e sustentações ambientais que podem retomar esse processo.

Mas como isso deve ser feito, considerando que os pacientes podem estar imaturos de diversas maneiras? Winnicott indica que nem sempre faz psicanálise, mas sempre faz psicoterapia com base na teoria psicanalítica 
do desenvolvimento, apoiado nas concepções fundamentais da psicanálise (o reconhecimento da existência e importância dos processos psíquicos inconscientes, a transferência e a resistência, bem como - para aqueles pacientes que já amadureceram a esse ponto - os problemas que derivam da administração da vida sexual nas relações interpessoais no quadro do cenário edípico). A psicanálise padrão, ou standard, é um trabalho a ser feito com aqueles que podem (afetiva, cognitiva e economicamente), ou seja, delimitando-os apenas no que se refere ao tipo de organização psíquica, os neuróticos, aqueles que estão integrados como pessoas inteiras e se relacionam com os outros, também apreendidos como pessoas inteiras, e encontram perturbações significativas na administração da vida instintual nessas relações interpessoais. A psicanálise modificada corresponde a todas as outras situações em que não é possível usar o método standard.

Nessa direção, Winnicott distingue três tipos pacientes, associando-os aos cuidados psicoterápicos aos quais devem ser submetidos: os neuróticos, isto é, aqueles que funcionam como pessoas inteiras e que têm problemas de administração da vida nas suas relações interpessoais, marcadas pelo cenário edípico, cujo tratamento consiste, grosso modo, ao método desenvolvido inicialmente por Freud; os deprimidos, aqueles que têm problemas de humor, que são recém-integrados na sua unidade como sujeitos, cujo tratamento é similar ao dos neuróticos, mas, aqui, a função central do analista é sobreviver, em termos afetivos, aos ataques e seduções que o paciente fizer; e, por fim, os psicóticos, ou não-integrados, cujo tratamento diz respeito à retomada da sustentação ambiental (tal como uma mãe sustenta seu bebê, tal como um ônibus é sustentado pela parte hidráulica) no quadro da reexperimentação de uma situação de dependência (1955/2000a). Como quadros complementares, ele ainda cita os borderline, que são pacientes que funcionam socialmente como neuróticos, mas têm problemas psicóticos, cujo tratamento implica inicialmente ultrapassar todas as defesas que foram estabelecidas (em geral, do tipo falso self) até que se possa chegar nas situações traumáticas mais primitivas (que quebraram, de forma significativa, sua continuidade de ser, aniquilando-os) ${ }^{3}$; os que têm atitude antissocial, aos quais tratamento é fornecer provisão ambiental que reconheça neles a situação de deprivação. Além disso, Winnicott ainda indica os pacientes que têm problemas psicossomáticos e de adicção ou similares, cujos tratamentos são complexos e envolvem uma sobreposição do que foi citado, como prescrição psicoterapêutica em todos os outros casos mencionados.

Falando, em termos gerais, sobre o que é a psicoterapia, sem especificar as diferenças específicas dos diferentes tipos de organização psicopatológica, Winnicott (1968/1975) dirá que ela 
ocorre na sobreposição entre a área do brincar do analista e a do paciente: "A psicoterapia trata de duas pessoas que brincam juntas" (p. 59). Quando o paciente não consegue brincar, o analista deve trabalhar para levá-lo a conquistar essa possibilidade. Brincar, aqui, é sinônimo de estar-com, compartilhar, comunicar e compreender, possibilitar um encontro verdadeiro com o paciente.

O analista fornecerá uma compreensão e um encontro humano que deve fazer o paciente se sentir visto em sua história e em seu sofrimento. Uma comunicação ou interpretação adequada corresponde a um tipo de sustentação ambiental:

Toda vez que comprendemos profundamente um paciente, e o mostramos através de uma interpretação correta e feita no momento certo, estamos de fato sustentando o paciente, e participando de um relacionamento no qual ele se encontra, até certo ponto, regredido ou dependente (1955/2000b, p. 354).

A partir da relação afetiva estabelecida entre o paciente e seu analista ou, noutros termos, a partir da transferência, $\mathrm{o}$ analista pode acompanhar o paciente na procura do sentido e origem dos seus sofrimentos, sentimentos e modos de ser, retomando sua história e refazendo suas formas de ser-estar. O objetivo do processo psicoterapêutico psicanalítico, para Winnicott, é fortalecer o paciente para que ele mesmo possa lidar com seus sofrimentos, lidar com sua vida se sentindo no comando desta.

\section{O fim de análise para Winnicott}

Uma análise deve, necessariamente, aspirar ao seu fim. Para o paciente, trata-se de encontrar um lugar (no mundo) para viver a partir de si mesmo, sentindo que ela lhe é própria e possível de ser vivida. Para o analista, trata-se de ter conseguido proporcionar o desenvolvimento emocional e levado o paciente até uma autonomia relativa, exercendo seu papel de reparador (o que certamente corresponde a uma necessidade afetiva significativa, no seu modo de ser na vida), estando, também com esse resultado, mais fortalecido para iniciar outro ou outros processos psicoterapêuticos.

Não se trata de ajustar ou modelar o paciente a um tipo ideal, dado que o horizonte para o qual procuramos nos dirigir não constitui uma moral, mas sim uma ética, apontando para princípios gerais relativos aos modos de ser-estar-no-mundo. Não diz respeito a esperar ou propagandear uma normalidade para o paciente, mas de encontrar um tipo de organização interna e relacional na qual o paciente possa se sentir relativamente livre, seja das suas pressões internas, instintuais e superegoicas, seja das externas, 
associadas aos seus relacionamentos inter-humanos (Winnicott, 1989/1994c, p. 58).

Esse estado dinâmico ao qual aspiramos que nossos pacientes possam chegar corresponde também à possibilidade de exercer certa flexibilidade ante a realidade, seja interna ou externa, podendo mudar suas estratégias de defesa contra as angústias existenciais e relacionais que caracterizam a existência humana. Sinteticamente e conceitualmente falando, na saúde, há uma flexibilidade enquanto na enfermidade há uma rigidez das organizações defensivas. Mais ainda, na saúde, por um lado, uma atitude natural de reação ao "prato feito", à "realidade dada", dado que o indivíduo sente como necessário criar, dar sentido e fazer o seu mundo; por outro lado, cabe ao estado de saúde uma integração que leva o indivíduo a se preocupar com o mundo, a prezar por determinadas relações (de objeto), de modo que o sentimento de culpa e a depressão seriam fenômenos necessariamente presentes (Winnicott, 1989/1994c).

Podemos, ainda nessa direção, apontar alguns outros aspectos que orientam ou caracterizariam esse horizonte ético, em termos de um telos psicoterapêutico. Cada pessoa tem suas singularidades, e essa obviedade deve, no entanto, estar associada, como parte da conquista própria ao desenvolvimento emocional, à compreensão daquilo que se é, da história que se tem, do que é possível e impossível a si mesmo em função das características próprias e da história que constitui a pessoa. Diz Winnicott (1986/1999a):

As pessoas têm que aceitar o que são e aceitar a história de seu desenvolvimento pessoal, justamente com as influências e atitudes ambientais locais; elas têm que continuar vivas e, vivendo, tentar se relacionar com a sociedade de modo a haver uma contribuição nos dois sentidos (p. 189).

Para finalizar essa exposição, quero, ainda, ressaltar a importância da aquisição de uma riqueza da personalidade e de uma vida cultural, como integrações que tornam a vida mais interessante de ser vivida, mesmo que seja uma vida sofrida. A riqueza de personalidade

354 Estilos clin., São Paulo, v. 23, n. 2, maio/ago. 2018, 344-361. 
consiste na aquisição da possibilidade de interação e comunicação associada a diversas áreas do conhecimento e da experiência (história, política, as artes em geral, o esporte etc.), o que implica, necessariamente, em adquirir conhecimento e familiaridade com esses campos. Essa riqueza de personalidade, meta desejável (com coloridos muito variáveis em cada caso), é tanto algo almejado para o desenvolvimento do paciente quanto uma característica necessária aos psicoterapeutas. Tal riqueza corresponde ou está associada à possibilidade de interagir com o outro, relacionando vida cultural e socialização, de modo que corresponderia ao estado de saúde a possibilidade de estar-com-o-outro, estar-no-mundo compartilhando-o consigo mesmo, sem ser aniquilado (Winnicott, 1965/1990).

Sem essa riqueza pessoal e cultural, um indivíduo que está restringido em si mesmo, rígido em suas defesas, inibido na possibilidade de agir, vive o legado cultural e a beleza do mundo, diz Winnicott (1957/1982), como um colorido torturante, impossivel de desfrutar (pp. 20-21).

Caberia, ainda, para caracterizar o fim de análise, considerar que o destino do analista (e mesmo da relação transferencial) nesse processo é o de ser desinvestido pelo paciente. Por um lado, o paciente se torna cada vez menos dependente e mais autônomo, cada vez mais tendo a necessidade de viver a intimidade e a comunicação 
(que ele pôde viver no processo analítico) noutros espaços e relacionamentos: o espaço analítico torna-se pequeno e limitado para o paciente e suas necessidades. Por outro, num sentido próximo a esse, a análise e o analista têm o mesmo destino que os objetos transicionais. Eles vão, pouco a pouco, perdendo seu interesse, são afastados sem serem recalcados ou lamentados, eles simplesmente perdem, gradualmente, a "aura" que os tornava tão vivos, tão interessantes, e tão necessários. Aquilo que Winnicott (1989/1994a) diz em relação ao destino dos objetos transcionais também serve para o analista e o espaço analítico, num fim de análise:

Os velhos soldados nunca morrem; apenas desvanecem. O objeto transicional tende a ser relegado ao limbo das coisas semi-esquecidas no fundo das gavetas da cômoda ou na parte de trás do armário de brinquedos. É costumeiro, contudo, que a criança saiba (p. 46).

Do ponto de vista do paciente, ele não precisa mais da análise (ainda que sempre possa retornar exatamente ao ponto em que deixou o analista e a análise, caso os acontecimentos da vida o levem a uma regressão); do ponto de vista do analista, este pode abrir espaço para reiniciar outro processo de cura.

\section{Parte III - Semelhanças e diferenças na compreensão de Freud e Winnicott sobre os objetivos do tratamento psicanalítico}

Winnicott considera que tudo que faz é freudiano "se houver algo que eu faça que não seja freudiano, gostaria de sabê-lo" (1989/1994b, p. 437) -, ainda que ele considere que as formulações metapsicológicas possam dar "uma aparência de compreensão onde tal compreensão não existe" (1987/1990, p. 51), o que, a meu ver, tenha feito com que ele evitasse as formulações metapsicológicas (cf. Fulgencio, 2018) e ampliasse as descritivas, 
enunciadas por Freud, sobre os objetivos do tratamento psicanalítico. Além disso, é necessário salientar que o modelo ontológico de Freud (a vida da alma é tal como se fosse um aparelho movido por forças e energias) e de Winnicott (a necessidade de ser e continuar sendo), tenham bases e estruturas diferentes, caracterizando o próprio sentido da existência de maneiras diferentes.

Nessa perspectiva, procurei mostrar que Freud pensa o objetivo do tratamento psicanalítico em termos de uma estabilidade do eu nas relações interpessoais, pressionadas pela vida instintual e pelos valores superegoicos (também referidos à sexualidade), enunciado tanto de forma metapsicológica quanto descritiva, tendo em vista a diminuição do sofrimento; e, que Winnicott, numa ampliação da proposta de Freud, aponta esse objetivo para além da vida instintual ou sexual (ainda que sem deixar de considerá-la), buscando a conquista de um lugar para ser e continuar sendo sem perda de si mesmo, adaptando-se ao mundo, embora sem perder a espontaneidade, mesmo que isso possa caracterizar uma vida sofrida.

\title{
THE OBJECTIVE OF PSYCHOANALYTICAL TREATMENT FOR FREUD AND FOR
} WINNICOTT

\begin{abstract}
This article aims at showing the general, theoretical, and descriptive aspects of the psychoanalytic treatment objectives according to Freud and Winnicott, to elucidate some continuities and ruptures in their conceptions on the goal of the psychoanalytic psychotherapeutic process. In this context, this study shows that Freud sees the objective of the psychoanalytic treatment as a stability of the self in interpersonal relationships under the pressure of the instinctual life and superegoic values (also related to sexuality) stated both in a meta-psychological and descriptive manner, aiming at reducing the suffering. Winnicott, expanding Freud's proposal, regards this goal as being beyond the instinctual and sexual life (although he takes it into account), searching a place to be and to continue to be, to feel real and live one's own life, even if this involves suffering.
\end{abstract}

Index terms: Freud; Winnicott; treatment; suffering; continuity of being.

\section{LOS OBJETIVOS DEL TRATAMIENTO PSICOANALÍTICO SEGÚN FREUD Y WINNICOTT}

\footnotetext{
REsumen

En este articulo se propone presentar los aspectos generales, teóricos y descriptivos de los objetivos del tratamiento psicoanalitico según Freudy W innicott, para explicitar algunas continuidades y rupturas en sus concepciones sobre el objetivo delproceso psicoterapéutico psicoanalítico. En este sentido, se busca demonstrar que Frend considera el objetivo del tratamiento psicoanalitico en términos de una estabilidad del yo en las relaciones interpersonales, presionadas por la vida instintiva o por valores superegoicos (también referidos a la sexualidad), enunciado tanto de manera metapsicológica como descriptiva, buscando la disminución del sufrimiento; y Winnicott, ampliando la propuesta de Freud, plantea ese objetivo más allá de la vida instintiva o sexual (sin dejar de considerarla), buscando la conquista de un lugar para ser y continuar a ser, sentirse real y llevando su propia vida, aunque implique sufrimiento.
}

Palabras clave: Freud; Winnicott; tratamiento; sufrimiento; continuidad de ser. 


\section{REFERÊNCIAS}

Ellenberger, H. F. (1970). The discovery of the unconscious. The history and evolution of dynamic psychiatry. New York, NY: Basic Books.

Freud, S. (1960). Correspondance 1873-1939. Paris, France: Gallimard.

Freud, S. (1998). Compte rendu de la comunication de G. Greve: "Sobre psicologia y psicoterapia de ciertos estados angustiosos". In S. Freud, Oeuvres complètes (Vol. 11, pp. 89-92). Paris, France: PUF. (Trabalho original publicado em 1911)

Freud, S. (2001). Freud's psycho-analytic procedure. In S. Freud, The standard edition of the complete psychological works of Sigmund Freud: "A case of hysteria", "Three essays on sexuality" and other works (Vol. 7, pp. 248-254). London, UK: Vintage Books. (Trabalho original publicado em 1904)

Freud, S. (2001). On the history of the psycho-analytic movement. In S. Freud, The standard edition of the complete psychological works of Sigmund Freud: "On the history of the post psychoanalytic movement", "Papers on metapsychology" and other works (Vol. 14, pp. 3-66). London, UK: Vintage Books. (Trabalho original publicado em 1914)

Freud, S. (2001). Analysis terminable and interminable. In S. Freud, The standard edition of the complete psychological works of Sigmund Freud: "Moses and the monoteism", "An outline of psycho-analisys" and other works (Vol. 23, pp. 211-254). London, UK: Vintage Books. (Trabalho original publicado em 1937)

Freud, S. (2001a). On beginning the treatment (Further recommendations on the Technique of Psycho-Analysis I). In S. Freud, The standard edition of the complete psychological works of Sigmund Freud (Vol. 12, pp. 122-144). London, UK: Vintage Books. (Trabalho original publicado em 1911-1913)

Freud, S. (2001b). The dynamics of transference. In S. Freud, The standard edition of the complete psychological works of Sigmund Freud: "The case of Schreber", "Papers on technique" and other works (Vol. 12, pp. 98-108). London, UK: Vintage Books. (Trabalho original publicado em 1911-1913)

Freud, S. (2001c). Types of onset of neurosis. In S. Freud, The standard edition of the complete psychological works of Sigmund Freud: "The case of Schreber", "Papers on technique" and other works (Vol. 12, pp. 229-238). London, UK: Vintage Books. (Trabalho original publicado em 1911-1913) 
Freud, S. (2001). The claims of psycho-analysis to scientific interest. In S. Freud, The standard edition of the complete psychological works of Sigmund Freud: "Totem and taboo" and other works (Vol. 13, pp. 164-190). London, UK: Vintage Books. (Trabalho original publicado em 1913)

Freud, S. (2001). The standard edition of the complete psychological works of Sigmund Freud: "Introductory letters on psycho-analisis" Parts I and II (Vol. 15). London, UK: Vintage Books. (Trabalho original publicado em 1916)

Freud, S. (2001a). The Ego and the Id. In S. Freud, The Standard Edition Of The Complete Psychological Works of Sigmund Freud: "The Ego and the Id" and other works (Vol. 19, pp. 3-66). London, UK: Vintage Books. (Trabalho original publicado em 1923)

Freud, S. (2001b). Two encyclopaedia articles. In S. Freud, The standard edition of the complete psychological works of Sigmund Freud: "Beyond the pleasure principle", "Group Psychology" and other works (Vol. 18, pp. 234-260). London, UK: Vintage Books. (Trabalho original publicado em 1923)

Freud, S. (2001). New introductory lectures on Psycho-Analysis. In S. Freud, The standard edition of the complete psychological works of Sigmund Freud: "New introductory lectures on psycho-analisys" and other works (Vol. 22, pp. 3-182). London, UK: Vintage Books. (Trabalho original publicado em 1933)

Freud, S., \& Breuer, J. (2009).Oeuvres complètes. Psychanalyse: Études sur l'hystérie et textes annexes (Vol. 2). Paris, France: PUF. (Trabalho original publicado em 1893-1895)

Freud, S., \& Ferenczi, S. (1992). Correspondance 1908-1914. Paris, France: Calmann-Lévy. Fulgencio, L. (Org.). (2018). A bruxa metapsicologia e seus destinos. São Paulo, SP: Blucher.

Gay, P. (1990). Freud et la liberté. In P. Gay, En lisant Freud, explorations et divertissements (pp. 79-101). Paris, France: PUF.

Green, A. (2005). Winnicott at the start of the third millennium. In L. Claadwell (Ed.), Sex and sexuality: winnicottian perspectives (Winnicott Studies Monograph Series, pp. 11-31). London, UK: Karnac Books.

Hale Jr., N. G. (Ed.). (1971). James Jackson Putnam and Psychoanalysis: Letters between Putnam and Sigmund Freud, Ernst Jones, William James, Sandor Ferenczi and Morton Prince, 1877-1917. Cambridge, MA: Harvard University Press.

Van Sweden, R. C. (1995). Regression to dependence: a second opportunity for ego integration and developmental progression. Northvale, NJ: Jason Aronson.

Winnicott, D. W. (1975). O brincar: uma exposição teórica. In D. W. Winnicott, O brincar \& a realidade (pp. 59-77). Rio de Janeiro, RJ: Imago. (Trabalho original publicado em 1968)

Winnicott, D. W. (1975). A criatividade e suas origens. In D. W. Winnicott, O brincar \& a realidade (pp. 95-120). Rio de Janeiro, RJ: Imago. (Trabalho original publicado em 1971)

Winnicott, D. W. (1982). Um homem encara a maternidade. In D. W. Winnicott, A criança e seu mundo (pp. 15-18). Rio de Janeiro, RJ: Zahar. (Trabalho original publicado em 1957)

Winnicott, D. W. (1983). Teoria do relacionamento paterno-infantil. In D. W. Winnicott, O ambiente e os processos de maturação (pp. 38-54). Porto Alegre, RS: Artmed, 1983. (Trabalho original publicado em 1960) 
Winnicott, D. W. (1983). Moral e educação. In D. W. Winnicott, O ambiente e os processos de maturação (pp. 88-98). Porto Alegre: Artmed. (Trabalho original publicado em 1963)

Winnicott, D. W. (1983). Os objetivos do tratamento psicanalítico. In D. W. Winnicott, O ambiente e os processos de maturação (pp. 152-155). Porto Alegre, RS: Artmed. (Trabalho original publicado em 1965)

Winnicott, D. W. (1984). Consultas terapêuticas em psiquiatria infantil (J. M. X. Cunha, trad.). Rio de Janeiro, RJ: Imago. (Trabalho original publicado em 1971)

Winnicott, D. W. (1990). From dependence towards independence in the development of the individual. In D. W. Winnicott, The maturational process and the facilitating environment (pp. 83-92). London, UK: Karnac Books. (Trabalho original publicado em 1965)

Winnicott, D. W. (1990). O gesto espontâneo. São Paulo, SP: Martins Fontes. (Trabalho original publicado em 1987)

Winnicott, D. W. (1990). Natureza humana. Rio de Janeiro, RJ: Imago. (Trabalho original publicado em 1988)

Winnicott, D. W. (1994a). O destino do objeto transicional. In C. Winnicott, R. Shepherd \& M. Davis (Orgs.), Exploraçóes psicanaliticas: D. W. Winnicott (pp. 44-48). Porto Alegre, RS: Artes Médicas. (Trabalho original publicado em 1989)

Winnicott, D. W. (1994b). Pós-escrito: D.W.W. sobre D.W.W. In C. Winnicott, R. Shepherd \& M. Davis (Orgs.), Exploraçôes psicanaliticas: D. W. Winnicott (pp. 433-443). Porto Alegre, RS: Artes Médicas. (Trabalho original publicado em 1989)

Winnicott, D. W. (1994c). Psiconeurose na infância. In C. Winnicott, R. Shepherd \& M. Davis (Orgs.), Exploraçōes psicanaliticas: D. W. Winnicott (pp. 53-58). Porto Alegre, RS: Artes Médicas. (Trabalho original publicado em 1989)

Winnicott, D. W. (1997). O primeiro ano de vida: concepçôes modernas do desenvolvimento emocional. In D. W. Winnicott, $A$ familia e o desenvolvimento individual (pp. 3-20). São Paulo, SP: Martins Fontes. (Trabalho original publicado em 1958)

Winnicott, D. W. (1997). Psiquiatria infantil, serviço social e atendimento alternativo. In D. W. Winnicott, Pensando sobre crianças (pp. 235-238). Porto Alegre, RS: Artes Médicas. (Trabalho original publicado em 1996) 
Winnicott, D. W. (1999). O conceito de indivíduo saudável. In D. W. Winnicott, Tudo começa em casa (pp. 3-22). São Paulo, SP: Martins Fontes. (Trabalho original publicado em 1971)

Winnicott, D. W. (1999). Variedades de psicoterapia. In D. W. Winnicott, Privação e delinquência (pp. 263-273). São Paulo, SP: Martins Fontes. (Trabalho original publicado em 1984)

Winnicott, D. W. (1999a). A cura. In D. W. Winnicott, Tudo começa em casa. São Paulo: Martins Fontes. (Trabalho original publicado em 1986)

Winnicott, D. W. (1999b). Vivendo de modo criativo. Tudo começa em casa (pp. 23-39). São Paulo, SP: Martins Fontes. (Trabalho original publicado em 1986)

Winnicott, D. W. (2000a). Aspectos clínicos e metapsicológicos da regressão no contexto psicanalítico. In D. W. Winnicott, Da pediatria à psicanálise: obras escolhidas (pp. 374-392). Rio de Janeiro, RJ: Imago. (Trabalho original publicado em 1955)

Winnicott, D. W. (2000b). Retraimento e regressão. In D. W. Winnicott, Da pediatria à psicanálise: obras escolhidas (pp. 347-354). Rio de Janeiro, RJ: Imago. (Trabalho original publicado em 1955)

\section{NOTAS}

1. Ainda que Freud, aqui, esteja se referindo ao método catártico, quando ele passa a mudar o método de tratamento, usando, então, o método psicanalítico, o objetivo final acaba sendo o mesmo.

2. Carta de Freud a James Jackson Putnam, de 7 de junho de 1915.

3. O livro de Robert Van Sweden, Regression to dependence: a second opportunity for ego integration and developmental progression (1995), parece conseguir resumir um aspecto central dos princípios e dos objetivos do tratamento psicanalítico para Winnicott.

lfulgencio@usp.br

Av. Prof. Mello Moraes, 1721

05508-030 - São Paulo - SP - Brasil.

Recebido em outubro/2017.

Aceito em agosto/2018. 